\title{
COMPETÊNCIA GERENCIAL DO ENFERMEIRO: CONHECIMENTO PUBLICADO EM PERIÓDICOS BRASILEIROS
}

\author{
Juliana Helena Montezeli ${ }^{1}$, Aida Maris Peres $^{2}$
}

\begin{abstract}
RESUMO: Pesquisa bibliográfica que objetivou analisar as publicações em periódicos brasileiros de 2001 a 2007 acerca da competência gerencial do enfermeiro. Utilizaram-se os descritores enfermagem/organização/administração para busca no LILACS e SCIELO, sendo encontrados 36 artigos, dos quais 20 enquadraram-se nos critérios de inclusão. Do agrupamento dos textos de acordo com enfoque gerência, emergiram duas categorias: A dicotomia entre a gestão e a atividade assistencial do enfermeiro; e A competência gerencial e a formação acadêmica do enfermeiro. Verificou-se que é essencial que o gerenciamento seja praticado pelos enfermeiros focado no cuidado, para tal é preciso mudança no fazer gestão e assistência, coerência entre a academia, o mundo do trabalho e a atitude profissional. Conclui-se que a visão anacrônica de alguns enfermeiros, instituições de saúde e de ensino superior representa obstáculo a ser vencido para a mobilização de competências gerenciais em prol do cuidado de enfermagem de qualidade.
\end{abstract}

PALAVRAS-CHAVE: Enfermagem; Organização; Administração; Publicações periódicas.

\section{NURSE'S MANAGERIAL COMPETENCE: KNOWLEDGE PUBLISHED IN BRAZILIAN PERIODICALS}

ABSTRACT: Bibliographical research that aimed to analyze the publications in Brazilian periodicals from 2001 to 2007 about the managerial competence of nurses. Using the descriptors nursing/organization/administration to search in LILACS and SciELO, 36 articles were found, 20 of which suited the inclusion criteria. From the grouping of the texts according to the focus given to management, 2 categories emerged: the dichotomy between the nurses' management and care activities and the nurses' managerial competence and academic training. It was verified that it is essential that the management conducted by nurses focus on the care, thus, for this to happen, a change is necessary in management and care, consistency between the academy, the world of the work and professional attitude. It was concluded that the anachronistic view of some nurses, health and higher education institutions is an obstacle that needs to be overcome for the mobilization of managerial skills looking for a quality nursing care.

KEYWORDS: Nursing; Organization; Administration; Periodicals publications.

\section{COMPETENCIA GERENCIAL DEL ENFERMERO: CONOCIMIENTO PUBLICADO EN PERIÓDICOS BRASILEROS}

RESUMEN: Investigación bibliográfica que tiene como objetivo analizar las publicaciones en periódicos brasileros de 2001 a 2007 acerca de la competencia gerencial del enfermero. Se utilizaron los descriptores enfermería/organización/ administración para búsqueda en el LILACS y SCIELO, habiendo sido encontrados 36 artículos, de los cuales 20 se encuadraron en los criterios de inclusión. Del agrupamiento de los textos de acuerdo con el enfoque gerencia, emergieron dos categorías: La dicotomía entre la gestión y la actividad asistencial del enfermero; y la competencia gerencial, y la formación académica del enfermero. Se verificó que es esencial que el gerenciamiento sea practicado por los enfermeros enfocado en el cuidado, para eso, es necesario mudanza en el hacer gestión y asistencia, coherencia entre la academia, el mundo de trabajo y la actitud profesional. Se concluye que la visión anacrónica de algunos enfermeros, instituciones de salud y de enseñanza superior representa un obstáculo a ser vencido para la movilización de competencias gerenciales en busca del cuidado de enfermería de calidad.

PALABRAS CLAVE: Enfermería; Organización; Administración; Publicaciones periódicas.

${ }^{1}$ Enfermeira. Mestranda do Programa de Pós-Graduação da Universidade Federal do Paraná-UFPR. Docente da Faculdade Evangélica do Paraná-FEPAR.

${ }^{2}$ Enfermeira. Doutora em Enfermagem. Mestranda do Programa de Pós-Graduação da UFPR. Docente da FEPAR. Professor Adjunto do Departamento de Enfermagem da UFPR.

Autor correspondente:

Juliana Helena Montezeli

Rua Itajubá, 644 - 81070-190 - Curitiba-PR

Recebido: 25/10/08

E-mail:jhmontezeli@hotmail.com

Aprovado: 24/06/09 


\section{INTRODUÇÃO}

Desde a concepção da enfermagem como profissão, o parcelamento do trabalho entre os diferentes membros da equipe teve na gerência o elo de articulação das atividades e de sua integração ao processo de trabalho em saúde como um todo. O processo de trabalho foi, desde então, organizado e controlado pelo enfermeiro com uso de instrumentos administrativos para alcançar as necessidades da clientela e as metas da organização na qual atua. Dessa forma, a gerência configura-se como ferramenta do processo cuidativo, pois busca organizar o trabalho e desenvolver condição para a realização da assistência de enfermagem ${ }^{(1)}$.

No entanto, na realidade emerge o obstáculo vivenciado por enfermeiros ao integrar a assistência às atividades gerenciais cotidianas. Historicamente 0 enfermeiro tornou-se um agente cuidador porém, na contemporaneidade, vem se firmando como administrador da assistência em detrimento das atividades cuidativas. Assim, na prática assistencial tem-se enfermeiros que perdem o contato com os pacientes e delegam aos auxiliares e técnicos de enfermagem atividades privativas de sua categoria. É fundamental reconhecer o cuidado como foco possível e necessário de ser gerenciado dentro das instituições em uma dimensão que extrapole o tecnicismo e incorpore conhecimento e atitudes de ordem racional e da esfera da sensibilidade ${ }^{(1)}$.

Outra vertente dessa temática está na dificuldade de muitas instituições de ensino superior adequarem a formação do enfermeiro às Diretrizes Curriculares Nacionaise formarem profissionais aptos a transformar a realidade na qual se inserem de maneira crítico-reflexiva ${ }^{(2)}$.

As Diretrizes Curriculares Nacionais-DCNs trazem no seu artigo quarto que a formação do enfermeiro objetiva desenvolver no profissional os conhecimentos para o exercício das seguintes competências e habilidades gerais: Atenção à saúde, Tomada de decisões, Comunicação, Liderança, Administração/gerenciamento e Educação permanente ${ }^{(2)}$.

Acrescenta-se nessa perspectiva que a gestão no processo de trabalho da enfermagem necessita ser fundamentada na reflexão crítica e aliada ao desenvolvimento do cuidado e deve ser cultivada ainda durante os anos da graduação. Dessa forma, a formação inicial do enfermeiro mostra-se como um importante caminho para superar a dicotomia entre teoria e prática ${ }^{(3)}$.

Tal percepção é acrescida da necessidade de fortalecimento da parceria entre ensino e serviço para a conformação de competências gerenciais, a fim de proporcionar o rompimento de paradigmas antagônicos entre o saber-fazer e o saber-pensar ${ }^{(3)}$.

Para organizar e controlar o processo de trabalho, o enfermeiro se instrumentaliza por meio do conhecimento técnico-administrativo desde o período de formação acadêmica. Entretanto, não se pode supervalorizar a gestão sem que ela seja voltada para a sustentação da qualidade assistencial, pois a função administrativa é essencial para a execução eficaz do cuidado de enfermagem, são duas práticas articuladas. Desta forma, não é possível que o enfermeiro administre sem assistir ${ }^{(1)}$. Portanto, faz-se necessário repensar o modelo de organização do trabalho em saúde, a fundamentação teórica para a prática e a produção de conhecimento com o intuito de fundamentar a prática da enfermagem com o cuidado como ponto central.

Vislumbra-se a excelência da formação profissional do enfermeiro, sobretudo com uma visão gerencial crítica, capaz de embasar um processo de trabalho coeso que possibilite o entrelaçamento de práticas administrativas e assistenciais de forma harmônica a fim de sanar as necessidades da clientela com a qual atua. Surge, com essas reflexões, o presente problema de pesquisa: quais as considerações trazidas pela literatura nacional acerca da articulação entre assistência e gerência no desenvolvimento do processo de trabalho em enfermagem?

Para responder ao problema de pesquisa traçouse como objetivo deste estudo: analisar a produção científica publicada em periódicos brasileiros indexados no período de 2001 a 2007 acerca da competência gerencial do enfermeiro.

\section{PERCURSO METODOLÓGICO}

Trata-se de uma pesquisa bibliográfica, construída com o percurso metodológico: escolha do tema, levantamento bibliográfico preliminar, formação do problema, elaboração do plano provisório de estudo, busca de fontes, leitura do material, fichamento, organização lógica do assunto e redação do texto.

Para dar início à busca dos artigos foram cruzados os descritores enfermagem/organização/ administração nas bases de dados LILACS e SCIELO, 
e foram encontradas 36 publicações em periódicos. Na sequência, realizou-se a leitura dos resumos e então foram selecionados os artigos que se enquadravam nos seguintes critérios: 1) ser uma publicação brasileira compreendida entre os anos de 2001 e 2007, uma vez que as DCNs foram publicadas em 2001; 2) discutir o gerenciamento em enfermagem nas esferas da formação e/ou serviço.

Dos 36 artigos encontrados, 20 enquadraramse nos critérios supracitados e para análise do material, emergiram 2 categorias, agrupando os textos de acordo com o principal enfoque dado à competência gerencial do enfermeiro. A primeira categoria diz respeito à dicotomia entre a gestão e a atividade assistencial do enfermeiro e a segunda discorre acerca da competência gerencial e a formação acadêmica desse profissional.

Finalizada a leitura seletiva, iniciou-se a leitura analítica e interpretativa a fim de possibilitar a construção dos resultados bem como sua discussão.

\section{RESULTADOS E DISCUSSÃO}

\section{A dicotomia entre a gestão e a atividade assistencial do enfermeiro}

O processo de trabalho em enfermagem pesquisa três áreas: o cuidado, o ensino e o gerenciamento, todas direcionadas para uma mesma finalidade que é o cuidado à necessidade do ser humano. Para tal, deve haver uma integração entre essas três esferas, pois todas ocupam o mesmo grau de importância. Assim, percebe-se que tais ações são complementares para resultar na finalidade da profissão(4).

Além das três vertentes mencionadas, o processo de trabalho em enfermagem almeja também que os sujeitos sociais atuem de forma emancipadora, com intervenções mais decisivas na construção do SUS ${ }^{(5)}$.

Diante do exposto, evidencia-se uma intrínseca relação entre as atividades administrativas e o cuidado de enfermagem, que quando realizado efetivamente, torna-se visível inclusive aos administradores hospitalares $^{(6)}$. No entanto, apesar de o enfermeiro estar envolvido na assistência direta ao paciente, existem momentos em que a sobrecarga administrativa o afasta do cuidado e dos processos educativos. Muitas vezes, isso pode ocorrer devido ao fato desse profissional abraçar problemas de outros membros da equipe e atender às expectativas institucionais em detrimento da concretização dos objetivos de seu próprio serviço ${ }^{(7)}$.
O processo de trabalho nas instituições de saúde é determinado com base na lógica de mercado e centrado no modelo clínico. Ao desvincular a prática administrativa do cuidado, o enfermeiro abre precedente para que suas atividades sejam subordinadas a outra categoria profissional. Assim, o processo de trabalho em enfermagem mostra-se realizado por diferentes categorias profissionais, parcelado e hierarquizado o que evidencia uma cisão entre o planejamento e a realização do cuidado $^{(8)}$.

Praticar a enfermagem considerando assistência e gestão como estanques pode ser interpretado como um ato infrator à ética da profissão pois, segundo seu código, toda atividade do enfermeiro deve ter como foco a clientela e pressupõe que os agentes de trabalho da enfermagem estejam aliados aos usuários na luta por uma assistência de qualidade, sem riscos e acessível a toda a população. Nesse prisma, o exercício da função gerencial pelo enfermeiro tem gerado polêmica na profissão, fato que se avulta conforme se torna evidente a dicotomia existente entre o que se espera do enfermeiro pelos teóricos de enfermagem e o que se verifica na sua práxis cotidiana. Sendo assim, o enfermeiro deve prender-se à assunção da função gerencial centrada no cuidado ao paciente, executando o previsto na Lei do Exercício Profissional sem perder de vista uma atuação fundamentada nos valores da profissão, no seu Código de Ética e nos direitos do paciente ${ }^{(9)}$.

A administração atual alicerça suas bases científicas no fazer, sendo assim, os enfermeiros gestores da era moderna privilegiam, sobretudo a competência técnica na assistência ao cliente. Geralmente, essa prática vincula-se a relações de autoritarismo que se configura na superioridade e na subordinação dos demais membros da enfermagem o que pode culminar no conformismo dos sujeitos e no cancelamento da possibilidade de uma atuação participativa dos mesmos. Defende-se que o trabalho de enfermagem, assistencial e gerencial, não pode anular as relações de independência dos seus protagonistas $^{(10)}$.

Uma das formas para que o cuidado seja realmente o centro do processo gerencial é a participação ativa de todas as categorias de enfermagem no planejamento do processo de trabalho, o gerenciamento em equipe, o qual é caracterizado pela comunicação aberta, compreensão mútua, satisfação, competência, consenso, criatividade e inovação no ambiente de trabalho ${ }^{(11)}$. Entretanto, muitos 
enfermeiros acomodam-se e tornam-se passivos diante da necessidade de reciclar suas atividades administrativas, contentando-se em limitá-las a atos burocráticos cotidianos e não buscam novas formas de proporcionar um trabalho mais coeso entre os membros da equipe ${ }^{(1)}$.

O saber-fazer em enfermagem encontra contradições ligadas às raízes da profissão. Nesse pensamento, a gerência não é algo isolado, pois é realizada pelo enfermeiro como sujeito social, sendo necessário explorar as divergências diante do ser humano e do exercício da gerência, uma vez que as manifestações corpóreas e culturais também ocorrem no desenvolvimento dessa atividade. Assim, é fundamental uma prática reflexiva diária e integrativa tendo no cuidado o ponto central da função administrativa $^{(12)}$.

A grande maioria dos problemas encontrados nas instituições de saúde concernente à qualidade assistencial prestada pode encontrar fundamento em uma prática gerencial ineficaz por parte dos enfermeiros. Tal realidade ocorre devido ao fato desses profissionais, muitas vezes, administrarem seu processo de trabalho por meio do "feeling", sem o uso de método, ferramentas e técnicas com fundamentação científica ${ }^{(13)}$.

Em um estudo ${ }^{(14)}$, ao avaliar a implementação de um modelo empírico de gestão em um hospital, encontrou dentre os focos de atenção o papel do enfermeiro centrado em ações à distância do paciente. Destaca-se a importância da revisão dos processos de trabalho bem como a reestruturação organizacional do Serviço de Enfermagem ${ }^{(14)}$.

Muitas são as estratégias que podem ser utilizadas para praticar a gerência em prol de uma assistência de melhor qualidade. Salienta-se a identificação da complexidade da clientela para adequar o dimensionamento de pessoal de enfermagem. Além disso, o conhecimento do perfil assistencial pode subsidiar o planejamento e a implementação de programas de cuidado para melhor atender às necessidades dos clientes e auxiliar na distribuição diária e na capacitação dos recursos humanos de enfermagem para o atendimento de cada grupo de pacientes ${ }^{(15)}$.

Complementando, tem-se que as tecnologias do trabalho de gerência devem ser unidas a dispositivos gerenciais que possam romper com visões anacrônicas do que seja gerenciar um serviço de saúde. Mais do que questionar o que ocorre nesses serviços deve-se criar novas indagações que gerem oportunidade para que o trabalhador coletivo (equipe) possa criar modos novos para organizar e realizar o processo de trabalho na enfermagem ${ }^{(16)}$.

O gerenciamento com vistas à melhoria da qualidade do cuidado, dentre outros benefícios, culmina em uma prática humanizada ${ }^{(17)}$. Ao romper a dicotomia existente entre gerenciar e assistir se proporciona um cuidado mais humano e há também a possibilidade de criar novas tecnologias para administrar com foco na assistência de qualidade ${ }^{(18)}$. Nesse sentido, é importante que o enfermeiro repense sua práxis e a adeque tendo o cuidado como eixo norteador do seu processo de trabalho ${ }^{(7)}$.

As informações até aqui apresentadas foram reunidas em um estudo ${ }^{(1)}$ no qual as autoras, ao afirmarem que as funções gerenciais do enfermeiro geralmente são confusas, diluídas e um tanto distantes dos pacientes, refletem, por consequência, na qualidade do cuidado prestado. Para romper esse paradigma, é fundamental reconhecer o cuidado e a relação entre os membros da equipe de enfermagem como elementos possíveis de serem gerenciados dentro da instituição, de maneira a extrapolar o tecnicismo e a tecnoburocracia.

O gerenciamento realizado apenas com a lógica e controle mecânico das atividades (muitas vezes executadas por outros agentes) não encontra eco no perfil de enfermeiro exigido na atualidade. Assim, fazer o gerenciamento do cuidado implica em tê-lo como pilar mestre das ações de enfermagem, utilizando os saberes administrativos e as novas tecnologias em prol de sua excelência. Para tal, faz-se necessário o envolvimento dos trabalhadores e da equipe de enfermagem a fim de que haja mudanças no fazer gestão e assistência com criatividade e autonomia.

\section{A competência gerencial e a formação acadêmica do enfermeiro}

Define-se competência profissional como a capacidade de "mobilizar, articular, colocar em ação valores, conhecimentos e habilidades necessários para o desempenho eficiente e eficaz de atividades requeridas pela natureza do trabalho"(2:37). Entretanto, muitas organizações ainda não consideram esse o perfil ideal de trabalhador, principalmente ao se falar do enfermeiro inserido nos serviços de saúde. A lógica mercadológica enfatiza a mão-de-obra capacitada em detrimento à formação crítico-reflexiva. Percebe-se, 
portanto, a divisão entre ensino e serviço, o que gera uma situação paradoxal na gestão do processo de trabalho em enfermagem ${ }^{(3)}$.

Mesmo diante dessa realidade, é fato que a administração convencional realizada por meio de regras estabelecidas tem sido, na contemporaneidade, cada vez mais substituída pela aplicação de conceitos como aprendizagem, conhecimento e competência, a fim de garantir a posição de vantagem das organizações atuais. Nesse contexto, o enfermeiro torna-se o elo de comunicação que objetiva o gerenciamento adequado e conecta as expectativas da alta gerência com as dos trabalhadores da linha de frente. Para tal atividade, o conteúdo do conhecimento desse profissional tem aumentado no âmbito administrativo, o que reflete progressivamente na necessidade de readequação do processo formativo ${ }^{(19)}$.

A divisão do trabalho em enfermagem, desde $o$ advento da profissão, traz o enfermeiro como figura responsável pela atuação administrativa. Os saberes acerca do gerenciamento originaram-se a partir da necessidade de organizar os hospitais e foram historicamente incorporados como função do enfermeiro. Dessa maneira, o preparo para desenvolver tal papel sempre permeou seu processo formativo ${ }^{(3)}$.

Além dos obstáculos impostos pelo mercado, outra dificuldade advém do desafio de mudar as práticas pedagógicas no ensino da Enfermagem, o qual ainda fundamenta-se na educação transmissional ao invés da construção do conhecimento ${ }^{(3)}$. Sendo assim, a relação teórico-prática permanece embrionária no país, sobretudo no que se refere às atividades administrativas do enfermeiro.

O enfoque disciplinar nos cursos de graduação é resultado de uma postura científica que promoveu a excessiva especialização e fragmentação, fato que resultou em alienação e depauperamento do ser humano. Por consequência, o conhecimento acaba sendo fragmentado pela própria estrutura universitária e isto dificulta o convívio na diversidade e torna a gestão um grande desafio ao enfermeiro inserido nesse universo. A superação dessa realidade pode ser viabilizada com o advento da interdisciplinaridade, uma vez que esta permite a construção ou reconstrução do conhecimento e colabora para que, ao final da trajetória acadêmica, o enfermeiro esteja apto a pensar e renovar sua realidade de atuação ${ }^{(20)}$ para que o cliente seja assistido integralmente.

Nessa ótica, para a construção da competência gerencial no profissional enfermeiro é essencial a integração de três situações. A primeira alicerça-se na questão de que os cursos de graduação devem estimular o desenvolvimento da visão gerencial no aluno na busca de transformá-lo em um indivíduo crítico-reflexivo na sua prática cotidiana. A segunda situação diz respeito às instituições de saúde, as quais precisam incentivar e desenvolver o perfil gerencial do enfermeiro, pois, dentre tantas vantagens nessa atitude, tem-se o fato de que a formação do enfermeiro para uma prática gerencial sustentada pela cientificidade colabora não somente para a garantia da qualidade da assistência prestada, como também para a manutenção da saúde do profissional e sua equipe $^{(21)}$. Por fim, é necessário que os próprios enfermeiros busquem continuamente conhecimentos para sustentarem cientificamente sua atuação como gestores do seu processo de trabalho ${ }^{(22)}$.

Em síntese, para que a competência gerencial do enfermeiro desenvolva-se na sua totalidade, deve haver coerência entre a sua trajetória acadêmica, o mundo do trabalho e a atitude dos profissionais ao longo de sua carreira.

\section{CONSIDERAÇÕES FINAIS}

O gerenciamento em enfermagem corresponde a um dos pilares de sustentação para uma assistência convergente com a qualidade exigida pela clientela atendida nos serviços de saúde dos tempos atuais. Nesse contexto, as concepções de gestão e de cuidado ainda são vistas como estanques por muitos enfermeiros, expressando a divisão do trabalho e culminando na dicotomia administração e assistência na vivência cotidiana desse profissional. No entanto, a análise interpretativa dos textos científicos produzidos sobre a temática apresenta a preocupação dos autores em mudar essa situação.

O objetivo proposto pelo estudo foi alcançado e a interpretação dos textos científicos proporcionou reflexões acerca da temática. Todavia, percebe-se que a visão anacrônica dos enfermeiros bem como de muitas instituições formadoras ainda representam um obstáculo a ser vencido para a real consolidação das propostas das DCNs no tocante à competência gerencial dessa categoria profissional.

Dessa forma, espera-se que os conhecimentos aqui apresentados possam subsidiar um processo de transformação dos enfermeiros, a fim de que esses vençam o obstáculo imposto por muitas instituições e 
exerçam a competência gerencial com vistas ao cuidado de sua clientela. Sabe-se, contudo, que para o alcance disto será preciso enfrentamento e superação, sendo fundamental à categoria desvestir a roupa velha do comodismo em busca da ocupação dos espaços da enfermagem e do comprometimento social com o exercício da cidadania.

\section{REFERÊNCIAS}

1. Rossi FR, Silva MADS. Fundamentos para processos gerenciais na prática de cuidado. Rev Esc Enferm USP. 2005;39(4):460-8.

2. Brasil. Resolução n. 3, de 7 de novembro de 2001. Dispõe sobre as diretrizes curriculares nacionais do curso de graduação em enfermagem. Diário Oficial da República Federativa do Brasil, Brasília, 9 nov. 2001. Seção 1, p. 37.

3. Peres AM, Ciampone MHT. Gerência e competências gerenciais do enfermeiro. Texto Contexto Enferm. 2006;15(3):492-9.

4. Marcon PM, Lacerda MR, Meier MJ. Uma reflexão sobre processo decisório no gerenciamento dos serviços de enfermagem. Cogitare Enferm. 2004 Jan/Jun;9(2):82-8.

5. Mishima SM, Villa TCS, Silva EM, Gomes ELR, Anselmi ML, Pinto IC, et al. Organização do processo gerencial no trabalho em saúde pública. In: Almeida MCP, Rocha SMM, organizadoras. O trabalho de enfermagem. São Paulo: Cortez; 1997. p. 251-96.

6. Bernardes A, Nakao JRS, Évora YDM. O trabalho administrativo do enfermeiro sob a ótica dos administradores hospitalares. Rev Esc Enferm Anna Nery. 2002;6(1):63-72.

7. Wehbe G, Galvão CM. O enfermeiro de unidade de emergência de hospital privado: algumas considerações. Rev Latino-Am Enferm. 2001;9(2):86-90.

8. Rocha AM. A saúde do trabalhador de enfermagem sob a ótica da gerência: obstáculos e possibilidades [tese]. São Paulo (SP): Escola de Enfermagem, Universidade de São Paulo; 2003.

9. Trevizan MA, Mendes IAC, Lourenço MR, Shinyashiki GT. Aspectos éticos na ação gerencial do enfermeiro. Rev Latino-Am Enferm. 2002;10(1):85-9.

10. Mendes IAC, Trevizan MA, Shinyashiki GT, Nogueira MS. O referencial da educação popular na ação gerencial e de liderança do enfermeiro. Texto Contexto Enferm. 2007;16(2):303-6.

11. Marques MC, Melo MRAC. O grid gerencial: uma análise descritiva na área da enfermagem. Rev Esc Enferm Anna Nery. 2004;8(2):275-8.

12. Prochnow AG, Leite JL, Trevizan MA. Manifestações culturais e corpóreas do enfermeiro na sua prática gerencial. Texto Contexto Enferm. 2006;15(3):449-57.

13. Svaldi JSD, Lunardi Filho WD. Métodos, ferramentas e técnicas da gestão da qualidade total: aplicação na organização do trabalho da enfermagem em um serviço de pronto atendimento. Texto Contexto Enferm. 2003;12(4):510-8.

14. Siqueira ILCP. Avaliação de um modelo empírico de gestão implantado em unidades de internação de um hospital privado [tese]. São Paulo (SP): Escola de Enfermagem, Universidade de São Paulo; 2003.

15. Fugulin FMT, Gaidzinski RR, Kurcgant P. Sistema de classificação de pacientes: identificação do perfil assistencial dos pacientes das unidades de internação do HU-USP. Rev Latino-Am Enferm. 2005;13(1):72-8.

16. Fracolli LA, Egry EY. Processo de trabalho de gerência: instrumento potente para operar mudanças nas práticas de saúde? Rev Latino-Am Enferm. 2001;9(5):13-8.

17. Aquino CP, Caregnato RC. A percepção das enfermeiras sobre a humanização na assistência perioperatória. Rev SOBECC. 2005;10(2):16-21.

18. Oliveira MAN. A humanização no gerenciamento de novas tecnologias por enfermeiras de centro cirúrgico. Rev SOBECC. 2005;10(4):8-12.

19. Shinyashiki GT, Trevizan MA, Mendes IAC. Sobre a criação e a gestão do conhecimento organizacional. Rev Latino-Am Enferm. 2003;11(4):499-506.

20. Mazon L, Trevizan MA. Fecundando o processo da interdisciplinaridade na iniciação científica. Rev LatinoAm Enferm. 2001;9(4):83-7.

21. Felli VEA. A saúde do trabalhador e o gerenciamento em enfermagem [tese]. São Paulo (SP): Escola de Enfermagem, Universidade de São Paulo; 2002.

22. Lourenço MR, Shinyashiki GT, Trevizan MA. Gerenciamento e liderança: análise do conhecimento dos enfermeiros gerentes. Rev Latino-Am Enferm. 2005;13(4):469-73. 